\title{
Biochemical and Structural Characterization of a Schiff Base in the Radical-Mediated Biosynthesis of 4-Demethylwyosine by TYW1
}

\author{
Tsehai A. J. Grell, ${ }^{\dagger, \perp}$ Anthony P. Young, ${ }^{\|, \perp}$ Catherine L. Drennan, ${ }^{*},,+, \S_{\odot}$ and Vahe Bandarian ${ }^{*}, \|_{\odot}$ \\ ${ }^{\dagger}$ Department of Chemistry, "Department of Biology, and ${ }^{\S}$ Howard Hughes Medical Institute, Massachusetts Institute of Technology, \\ Cambridge, Massachusetts 02139, United States \\ "Department of Chemistry, University of Utah, Salt Lake City, Utah 84112, United States
}

Supporting Information

\begin{abstract}
TYW1 is a radical S-adenosyl-L-methionine (SAM) enzyme that catalyzes the condensation of pyruvate and $\mathrm{N}$-methylguanosine to form the posttranscriptional modification, 4-demethylwyosine, in situ on transfer RNA (tRNA). Two mechanisms have been proposed for this transformation, with one of the possible mechanisms invoking a Schiff base intermediate formed between a conserved lysine residue and pyruvate. Utilizing a combination of mass spectrometry and X-ray crystallography, we have obtained evidence to support the formation of a Schiff base lysine adduct in TYW1. When ${ }^{13} \mathrm{C}$ labeled pyruvate is used, the mass shift of the adduct matches that of the labeled pyruvate, indicating that pyruvate is the source of the adduct. Furthermore, a crystal structure of TYW1 provides visualization of the Schiff base lysine-pyruvate adduct, which is positioned directly adjacent to the auxiliary [4Fe-4S] cluster. The adduct coordinates the unique iron of the auxiliary cluster through the lysine nitrogen and a carboxylate oxygen, reminiscent of how the radical SAM [4Fe-4S] cluster is coordinated by SAM. The structure provides insight into the binding site for tRNA and further suggests how radical SAM chemistry can be combined with Schiff base chemistry for RNA modification.
\end{abstract}

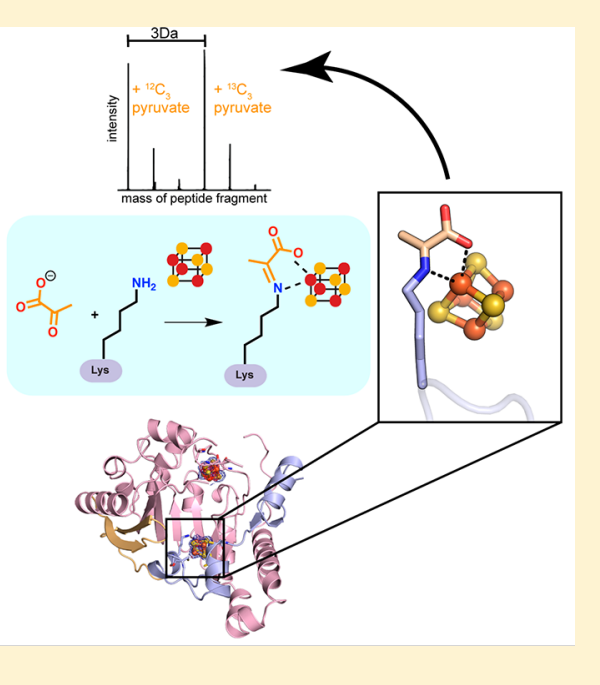

\section{INTRODUCTION}

In addition to the four canonical RNA bases, transfer RNA (tRNA) molecules are adorned with a wide variety of posttranscriptionally modified bases, which range in complexity from methylations to hypermodifications and may require the actions of several enzymes, such as the eight-step transformation involved in the biosynthesis of the modified base, queuosine. $^{1-8}$ These modifications expand the chemical repertoire of nucleobases and have also been implicated in the stabilization of tRNA structure and the maintenance of function. ${ }^{9,10}$ In fact, many hypermodified bases occur at or adjacent to the anticodon loop, where they are thought to be involved in modulating codon-anticodon interaction or stability. ${ }^{11}$ The nucleoside wyosine is a hypermodified base that contains a characteristic imidazopurine (tricyclic) core (Scheme 1). ${ }^{12-15}$ Wyosine derivatives are found at position 37 of the anticodon stem loop (ACSL) of tRNA ${ }^{\text {Phe }}$ molecules from archaea and eukarya. ${ }^{16-18}$ The presence of the large hydrophobic bulky base in position 37 , which is adjacent to the wobble base in the anticodon loop, has been shown to be important in preventing frameshifts. ${ }^{19,20}$

The simplest wyosine derivative, 4-demethylwyosine (imG14), is found as both a modified tRNA base in some archaeal species and an intermediate on the pathway to more complex wyosine derivatives $^{12,16-18,21-29}$ (Scheme 1). In vivo, imG-14 is biosynthesized from guanosine by the successive actions of two enzymes, the $S$-adenosyl-L-methionine (SAM) dependent methyl transferase TRM5 and the radical SAM enzyme TYW1. ${ }^{17,18,30,31}$ TRM5 methylates the genetically encoded guanosine residue at $\mathrm{N} 1$ creating $\mathrm{N}$-methylguanosine $\left(\mathrm{m}^{1} \mathrm{G}\right){ }^{30,31}$ whereas TYW1 adds $\mathrm{C} 2$ and $\mathrm{C} 3$ of pyruvate to $\mathrm{m}^{1} \mathrm{G}$ via a radical mechanism, forming the characteristic tricyclic ring of all wyosine derivatives. ${ }^{32-37}$ The identity of pyruvate as the source of the carbons in the imidazoline ring was established using ${ }^{13} \mathrm{C}$ pyruvate isotopologues in vitro, which showed that $\mathrm{C} 2$ and $\mathrm{C} 3$ of pyruvate are incorporated into the tRNA base and C1 is lost as an unidentified side product, proposed to be either carbon dioxide or formate. ${ }^{33}$

TYW1, like other enzymes in the 100,000-plus membered radical SAM superfamily, ${ }^{38}$ uses a SAM-bound $[4 \mathrm{Fe}-4 \mathrm{~S}]$ cluster to reductively cleave SAM, forming methionine and a highly reactive $5^{\prime}$-deoxyadenosyl radical species (dAdo•) that initiates radical-based chemistry. ${ }^{39}$ TYW1 also has an auxiliary iron-sulfur cluster, identified as a $[4 \mathrm{Fe}-4 \mathrm{~S}]$ cluster by an electron paramagnetic resonance (EPR) and Mössbauer study. ${ }^{35}$ Additional or auxiliary iron-sulfur clusters have been identified in several characterized radical SAM enzymes involved in the biosynthesis of cofactors (e.g., biotin, ${ }^{40}$ lipoic acid, $^{41,42}$ and the molybdopterin cofactor ${ }^{43}$ ) and antibiotics, ${ }^{44}$

Received: February 6, 2018

Published: May 24, 2018 
Scheme 1. Biosynthetic Pathway for imG-14

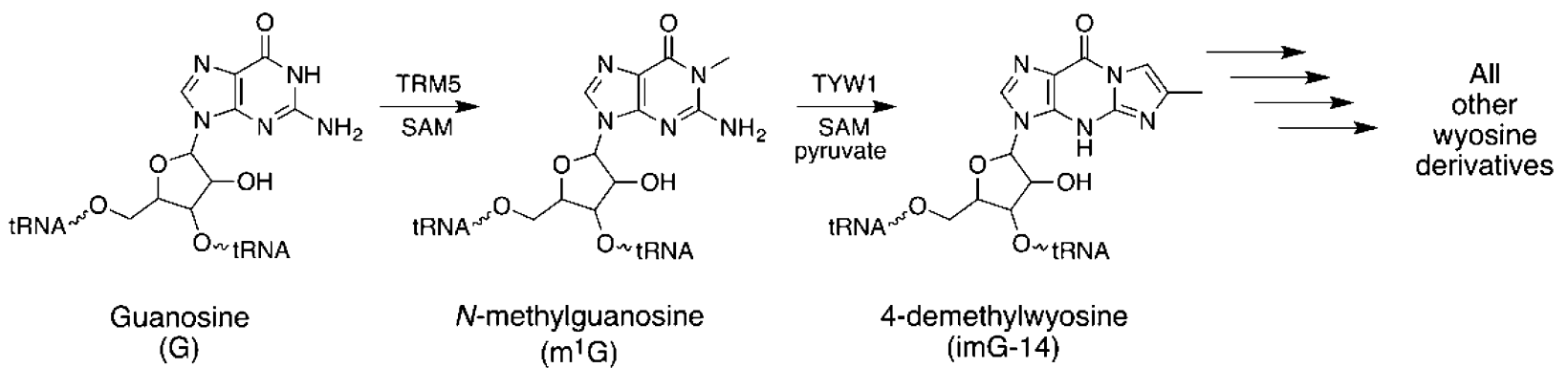

Scheme 2. Two Hypothesized Mechanisms for TYW1

1

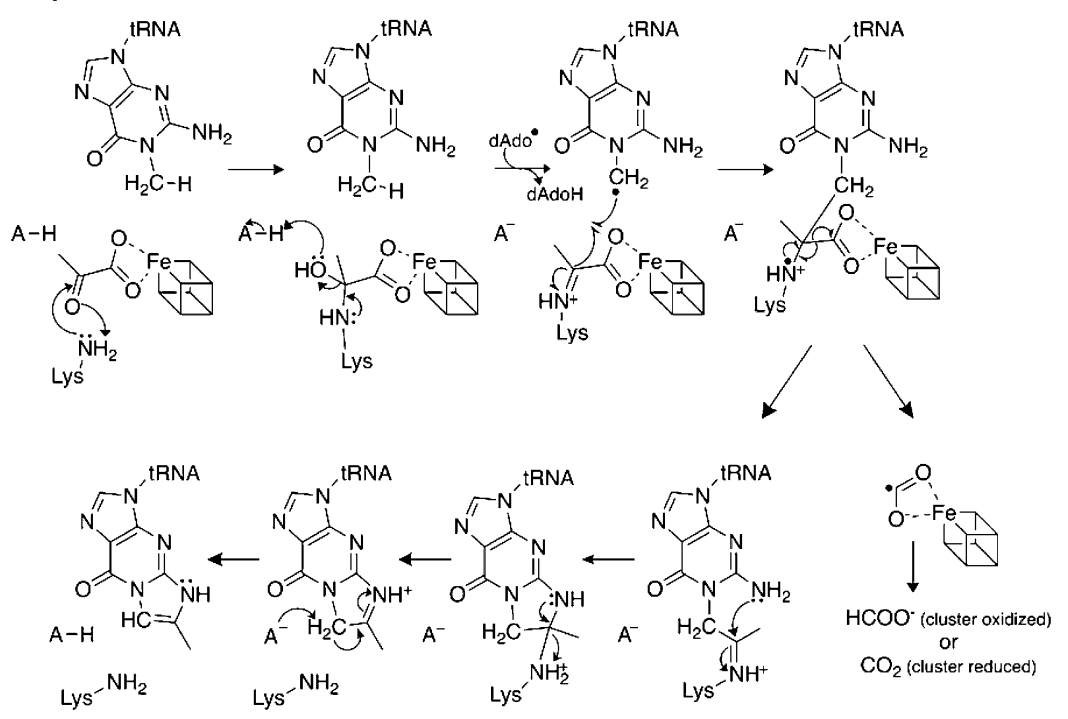

2

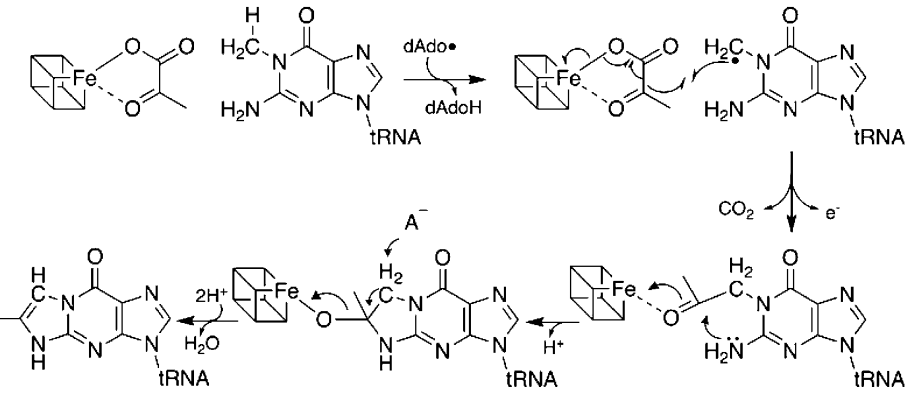

in the posttranslational modification of proteins, ${ }^{45,46}$ and in posttranscriptional modifications of RNA. ${ }^{47,48}$ A small subset of these enzymes also contain auxiliary $[4 \mathrm{Fe}-4 \mathrm{~S}]$ clusters that are ligated by three cysteine residues, leaving a site differentiated iron ion. In these cases, the enzymes are predicted to use the open coordination site to bind substrate, as seen in the structural and spectroscopic studies of molybdopterin biosynthetic enzyme MoaA. ${ }^{37,43,49}$ The auxiliary cluster in TYW1 is predicted to be ligated by three cysteine residues, leaving an open coordination site. ${ }^{50,51}$

Two competing mechanisms have been proposed for how TYW1 uses its [4Fe-4S] clusters to form the tricyclic ring of wyosine derivatives (Scheme 2). In one mechanism, pyruvate is activated by forming a Schiff base to a conserved Lys residue in the active site. Hydrogen atom abstraction from the methyl group of $\mathrm{m}^{1} \mathrm{G}$ by the dAdo radical, $^{32}$ which has been demonstrated biochemically, results in production of $5^{\prime}$. deoxyadenosine $(\mathrm{dAdoH})$ and a methylene radical. The methylene radical in turn attacks the $\mathrm{C} 2$ of the immobilized pyruvate. Homolytic cleavage of the $\mathrm{C} 1-\mathrm{C} 2$ bond of pyruvate eliminates the equivalent of a carbon dioxide anion radical. The carbon dioxide anion radical may then be oxidized to form carbon dioxide or reduced to form formate, with the auxiliary cluster possibly playing a role. The exocyclic amino group at C2 of guanosine resolves the Schiff base in a transimination reaction that regenerates the active site Lys for a subsequent turnover cycle. ${ }^{32,33}$

A competing mechanism has been proposed that discounts the role of the conserved Lys residue, proposing, on the basis of spectroscopic studies, that the auxiliary cluster alone facilitates the activation of pyruvate (Scheme 2). ${ }^{35,52}$ In this proposal, hydrogen atom abstraction also occurs at the methyl group of 
$\mathrm{m}^{1} \mathrm{G}$, consistent with the biochemical data, ${ }^{32}$ and the resulting radical species forms a bond with $\mathrm{C} 2$ of pyruvate, prompting homolytic cleavage of the $\mathrm{C} 1-\mathrm{C} 2$ bond of pyruvate. In this mechanism, decarboxylation is concomitant with reduction of the auxiliary cluster to form carbon dioxide. The auxiliary cluster is proposed to catalyze the formation of the imidazoline ring by activating the keto oxygen for elimination upon transimination. ${ }^{35,36}$ This mechanism does not provide a direct role for a catalytically essential lysine, which is proposed to play an indirect role in modulating the redox properties of the cluster. $^{36,37}$

A key difference between the two proposed mechanisms is the involvement of a Schiff base in mechanism 1. Here we employ crystallography and biochemistry to investigate the formation of a Schiff base between the conserved Lys in TYW1 and pyruvate.

\section{EXPERIMENTAL PROCEDURES}

Expression of Tobacco Etch Virus (TEV) Protease. The Escherichia coli SG1300009 pLacIRARE cell line was transformed with TEV (both generous gifts from Hazel Holden at University of Wisconsin-Madison) $)^{53}$ and plated on a lysogeny broth-Lennox (LB) agar plate containing $34 \mu \mathrm{g} / \mathrm{mL}$ chloramphenicol and $100 \mu \mathrm{g} / \mathrm{mL}$ ampicillin. A single colony from this plate was used to inoculate a 150 $\mathrm{mL}$ culture of LB containing $34 \mu \mathrm{g} / \mathrm{mL}$ chloramphenicol and $100 \mu \mathrm{g} /$ $\mathrm{mL}$ ampicillin that was grown overnight at $37{ }^{\circ} \mathrm{C}$ with shaking at 225 rpm.

The overnight culture was used to inoculate $122.8 \mathrm{~L}$ Fernbach flasks, each containing $1 \mathrm{~L}$ of $\mathrm{LB}$ containing $34 \mu \mathrm{g} / \mathrm{mL}$ chloramphenicol and $100 \mu \mathrm{g} / \mathrm{mL}$ ampicillin. They were grown at 37 ${ }^{\circ} \mathrm{C}$ with shaking at $200 \mathrm{rpm}$ until $\mathrm{OD}_{600} \sim 0.6$. The temperature was set to $16{ }^{\circ} \mathrm{C}$, and protein expression was induced by addition of isopropyl $\mathrm{B}$-D-1-thiogalactopyranoside to a final concentration of 0.1 $\mathrm{mM}$. After $18 \mathrm{~h}$, cells were harvested by centrifugation and flash frozen with liquid $\mathrm{N}_{2}$.

Purification of TEV Protease. TEV protease was purified at $4{ }^{\circ} \mathrm{C}$. Approximately $30 \mathrm{~g}$ of cells were resuspended in $50 \mathrm{mM}$ potassium phosphate (KPi) (pH 7.4) buffer containing $0.5 \mathrm{M}$ potassium chloride $(\mathrm{KCl}), 20 \mathrm{mM}$ imidazole, $20 \%(\mathrm{v} / \mathrm{v})$ glycerol, and $1 \mathrm{mM}$ phenylmethane sulfonyl fluoride (PMSF). Cells were lysed using a Branson sonificator at $50 \%$ amplitude with $15 \mathrm{~s}$ on and $59.9 \mathrm{~s}$ off, for a total of $12 \mathrm{~min}$ of lysis time, while stirring on ice. Cell lysate was clarified via centrifugation at $18,500 \times g$ at $4{ }^{\circ} \mathrm{C}$ for $30 \mathrm{~min}$.

The clarified lysate was loaded onto a $5 \mathrm{~mL}$ HiTrap chelating HP column charged with nickel sulfate and preequilibrated in $50 \mathrm{mM} \mathrm{KPi}$ (pH 7.4) buffer containing $0.5 \mathrm{M} \mathrm{KCl}, 20 \mathrm{mM}$ imidazole, and $20 \%$ (v/ v) glycerol. When all of the lysate was loaded, the column was washed with $50 \mathrm{~mL}$ of the above buffer. Protein was eluted with a gradient to $100 \% 50 \mathrm{mM} \mathrm{KPi}(\mathrm{pH} 7.4$ ) buffer containing $0.5 \mathrm{M} \mathrm{KCl}, 0.5 \mathrm{M}$ imidazole, and 20\% (v/v) glycerol over $40 \mathrm{~mL}$.

Fractions containing protein were identified via SDS-PAGE, and the concentrated fractions were pooled and then dialyzed against $4 \mathrm{~L}$ of 50 $\mathrm{mM} \mathrm{KPi}(\mathrm{pH} 7.4$ ) buffer containing $0.5 \mathrm{M} \mathrm{KCl}, 20 \mathrm{mM}$ imidazole, and $20 \%$ (v/v) glycerol at $4{ }^{\circ} \mathrm{C}$ with two changes. Glycerol was added to the protein to a final concentration of $50 \%(\mathrm{v} / \mathrm{v})$, and the protein was aliquoted and stored at $-20^{\circ} \mathrm{C}$. $^{53}$

Cloning and Expression of Wild Type TYW1 (wtTYW1). To create a wtTYW1 (pAY613) construct containing a TEV protease site, the codon optimized Methanocaldococcus jannaschii TYW1 gene was cut from pET28a (pAY429) ${ }^{33}$ using the HindIII and NdeI cut sites and inserted into pET28JT vector ${ }^{53}$ digested with HindIII and NdeI. Expression of wtTYW1 was as previously described. ${ }^{33}$

Purification of wtTYW1. wtTYW1 was purified in a Coy anaerobic chamber (approximately 97\% $\mathrm{N}_{2}, 3 \% \mathrm{H}_{2}$ ) at room temperature. Cell paste was resuspended in $20 \mathrm{mM}$ Tris(hydroxymethyl)aminomethane hydrochloride (Tris- $\mathrm{HCl})(\mathrm{pH} 8)$ and lysed by sonicating with a Branson sonicator at $50 \%$ amplitude for
15 min lysis time with $15 \mathrm{~s}$ on and $45 \mathrm{~s}$ off. Cell lysate was clarified by centrifugation at $18,500 \times g$ at $4{ }^{\circ} \mathrm{C}$ for $30 \mathrm{~min}$.

Clarified lysate was transferred to a sealed bottle and heated for 30 min in an $80^{\circ} \mathrm{C}$ water bath outside the anaerobic chamber and was then cooled for $15 \mathrm{~min}$ in an ice bath. The lysate was again clarified by centrifugation at $18,500 \times g$ at $4{ }^{\circ} \mathrm{C}$ for $30 \mathrm{~min}$.

Solid ammonium sulfate was added to the clarified lysate to a final concentration of $1 \mathrm{M}$, which was loaded onto a $40 \mathrm{~mL}$ butyl-sepharose FF column equilibrated in $20 \mathrm{mM}$ Tris- $\mathrm{HCl}$ ( $\mathrm{pH}$ 8) buffer containing $1 \mathrm{M}$ ammonium sulfate. Following loading of the lysate, the column was washed with equilibration buffer until the absorbance returned to baseline. Adsorbed protein was eluted with a step gradient to $20 \mathrm{mM}$ Tris- $\mathrm{HCl}(\mathrm{pH} 8)$, and brown fractions were pooled.

Pooled fractions were loaded onto two $5 \mathrm{~mL}$ HiTrap chelating HP columns connected in series charged with nickel sulfate and equilibrated in $50 \mathrm{mM} \mathrm{KPi}(\mathrm{pH} 7.4)$ buffer containing $0.5 \mathrm{M} \mathrm{KCl}$ and $50 \mathrm{mM}$ imidazole. The column was washed with equilibration buffer, and when absorbance had returned to baseline, the adsorbed protein was eluted by a step gradient to $50 \mathrm{mM} \mathrm{KPi} \mathrm{(pH} \mathrm{7.4)} \mathrm{buffer}$ containing $0.5 \mathrm{M} \mathrm{KCl}$ and $0.5 \mathrm{M}$ imidazole. Brown fractions were pooled and desalted into $50 \mathrm{mM}$ piperazine- $N, N^{\prime}$-bis(2-ethanesulfonic acid)-sodium hydroxide (PIPES-NaOH) ( $\mathrm{pH}$ 7.4) buffer containing 2 $\mathrm{mM}$ dithiothreitol (DTT).

The His-tag was removed by incubation overnight with TEV protease at room temperature. The solution was then loaded onto two $5 \mathrm{~mL}$ HiTrap chelating HP columns connected in series, charged with nickel sulfate, and equilibrated in $50 \mathrm{mM} \mathrm{KPi} \mathrm{(pH} \mathrm{7.4)} \mathrm{buffer}$ containing $0.5 \mathrm{M} \mathrm{KCl}$ and $50 \mathrm{mM}$ imidazole. The protein that flowed through the column was pooled and desalted into $50 \mathrm{mM}$ PIPES$\mathrm{NaOH}$ ( $\mathrm{pH}$ 7.4) buffer containing 2 mM DTT.

Protein concentrations were determined by the Bradford method, and a correction factor of 0.32 was applied. ${ }^{32}$ Reconstitution of iron sulfur clusters was performed with desalted TYW1 by stirring at room temperature in the presence of 10 molar equivalents of iron(III) chloride and sodium sulfide for $4 \mathrm{~h}$. Precipitated protein was then removed by centrifugation, and the protein was desalted into $50 \mathrm{mM}$ PIPES-NaOH (pH 7.4) buffer containing $150 \mathrm{mM} \mathrm{KCl}$ and $2 \mathrm{mM}$ DTT.

Desalted protein was loaded onto a Sephacryl 16/60 S-200 column equilibrated in $50 \mathrm{mM}$ PIPES-NaOH ( $\mathrm{pH}$ 7.4) buffer containing 150 $\mathrm{mM} \mathrm{KCl}$ and $2 \mathrm{mM}$ DTT. The peak corresponding to monomeric protein was pooled, concentrated, and flash frozen with liquid $\mathrm{N}_{2}$.

Expression of His-Tagged TYW1. TYW1 with an N-terminal His-tag was expressed using pAY429 as previously described. ${ }^{33}$

Purification of TYW1. TYW1 with an N-terminal His-tag was purified as described above for wild-type TYW1 with the following changes. The clarified lysate was heated to $80^{\circ} \mathrm{C}$ in a mineral oil bath within an anaerobic chamber in order to minimize exposure to oxygen. The TEV cleavage step was also omitted.

Preparation of SAM. SAM was prepared as described previously. ${ }^{33}$

Preparation of tRNA. Soluble RNA was extracted from a YPL207W knockout strain of Saccharomyces cerevisiae as previously described. $^{32}$

Crystallization of TYW1. His-tagged TYW1 was crystallized using the sitting-drop vapor diffusion method within an anaerobic chamber (MBraun) under a nitrogen atmosphere $\left(\mathrm{O}_{2}<0.1-1.2 \mathrm{ppm}\right)$ at $21^{\circ} \mathrm{C}$. All sparse matrix screening was performed using a Mosquito pipetting robot (TTP LabTech). In order to obtain data quality crystals, a microseed matrix screening technique was utilized. A microcrystal seed stock was prepared by mixing $1 \mu \mathrm{L}$ of protein solution (containing 8 $\mathrm{mg} / \mathrm{mL}$ of TYW1, $50 \mathrm{mM}$ PIPES $\mathrm{pH} 7.4,150 \mathrm{mM} \mathrm{KCl}, 2 \mathrm{mM}$ DTT, and $5 \mathrm{mM} \mathrm{SAM})$ with $1 \mu \mathrm{L}$ of reservoir solution $(0.2 \mathrm{M} \mathrm{K} / \mathrm{Na}$ tartrate tetrahydrate, $25 \%(\mathrm{w} / \mathrm{v})$ PEG 3350). The very thin plate-like crystals, which appeared after $24 \mathrm{~h}$, were harvested by pipetting the entire drop ( $2 \mu \mathrm{L}$ in total) into a seed bead tube (Hampton Research) containing $50 \mu \mathrm{L}$ of stabilization solution $(0.2 \mathrm{M}$ potassium sodium tartrate tetrahydrate, 30\% (w/v) PEG 3350). After vortexing for $2 \mathrm{~min}, 450 \mu \mathrm{L}$ of stabilization buffer was added to the tube to make the seed stock 
and serial dilutions were performed to prepare a 100 -fold and a 1000fold dilution for the microseed matrix screening experiments.

Data quality crystals were obtained in the screening tray by mixing $0.25 \mu \mathrm{L}$ of protein solution (containing $9.7 \mathrm{mg} / \mathrm{mL}$ of TYW1, $50 \mathrm{mM}$ PIPES pH 7.4, $150 \mathrm{mM} \mathrm{KCl,} 2 \mathrm{mM} \mathrm{DTT}$, and $5 \mathrm{mM}$ SAM) with 0.2 $\mu \mathrm{L}$ of reservoir solution $\left(100 \mathrm{mM} \mathrm{KH} \mathrm{PO}_{4} / \mathrm{Na}_{2} \mathrm{HPO}_{4} \mathrm{pH} 6.2,10 \%\right.$ (w/v) PEG 3000) and $0.05 \mu \mathrm{L}$ of the 1000 -fold diluted seed stock and incubating the mixture over a $70 \mu \mathrm{L}$ reservoir. Dark-brown rod-like $(50 \mu \mathrm{m} \times 100 \mu \mathrm{m} \times 40 \mu \mathrm{m})$ crystals appeared after 2 days. The tray was transferred to a Coy laboratory products' anaerobic chamber at 24 ${ }^{\circ} \mathrm{C}$ and under a $95 \%$ argon, $5 \%$ hydrogen atmosphere, for harvesting. Crystals were cryoprotected by transferring them in four steps of increasing glycerol concentration into a cryogenic solution containing $100 \mathrm{mM} \mathrm{KH}{ }_{2} \mathrm{PO}_{4} / \mathrm{Na}_{2} \mathrm{HPO}_{4} \mathrm{pH} 6.2,15 \%$ (w/v) PEG 3000, and $20 \%$ $(\mathrm{v} / \mathrm{v})$ glycerol before flash freezing in liquid nitrogen.

Structure Determination of TYW1. A native data set of TYW1 was collected at the Advanced Photon Source (Argonne, IL) on beamline $24-\mathrm{ID}-\mathrm{C}$ using the Pilatus-6M pixel array detector at a wavelength $0.9792 \AA(12662 \mathrm{eV})$ and a temperature of $100 \mathrm{~K}$. During data collection, the crystal was continuously translated along its major macroscopic axis, using the continuous vector strategy. Data were indexed, integrated, and scaled in $\mathrm{HKL} 2000^{54}$ in the spacegroup $P 2_{1} 2_{1} 2_{1}$ to $1.64 \AA$ resolution.

An initial model of TYW1 containing one molecule in the asymmetric unit was solved by molecular replacement in Phaser ${ }^{55}$ (LLG and TFZ scores of 1763.8 and 41.8, respectively) using the previously published structure of TYW1 from Methanocaldococcus jannaschii (PDB 2Z2U) as an all atom search model and the full resolution of the processed data set. After one round of rigid body refinement, ill-fitting sections of the initial model were deleted and the resulting model was subjected to 10 rounds of simulated annealing to minimize existing model bias. Iterative rounds of model building into unambiguous electron density and refinement were performed in $\mathrm{Coot}^{56}$ and Phenix ${ }^{57}$ respectively. In the initial stages of refinement, Coot was used to place the iron sulfur clusters, whereas water molecules were manually added during advanced stages of refinement. Positive $F_{o}-F_{c}$ difference density was used to guide the modeling of the covalent adduct formed at K41. A new residue was created by merging a pyruvate molecule and lysine molecule to produce a Schiff base ligand, KAC, in Jligand. ${ }^{58}$ Coot was used to dock the ligand into the structure. In addition to preparing the residue, respective link records and CIF files used during docking and refinement were prepared in Jligand.

Verification of the final structure was guided by simulated annealing composite omit maps and analysis of Ramachandran and rotamer outliers. Side chains without visible density were stubbed at the last visible atom, and residues without unambiguous electron density were not included in the model. This refinement procedure resulted in a final structure of TYW1 that includes residues $0-72,82-255$, and 260-311 (of 331 residues including the purification tag and linker), a $[2 \mathrm{Fe}-3 \mathrm{~S}]$ radical SAM cluster, and a $[4 \mathrm{Fe}-4 \mathrm{~S}]$ auxiliary cluster. It contained $96.9 \%$ of its residues in the most favored region of the Ramachandran plot, $3.1 \%$ in the additionally favored region, and $0.0 \%$ in the outlier region. $R_{\text {work }}$ and $R_{\text {free }}$ are 0.1760 and 0.2024 , respectively. All refinement statistics are summarized in Table S1. The radical SAM and the auxiliary clusters were refined with occupancies of 0.84 and 0.58 , respectively, indicating that about $80 \%$ of molecules in the crystal contained a [2Fe-3S] radical SAM cluster and about $60 \%$ have a $[4 \mathrm{Fe}-4 \mathrm{~S}]$ auxiliary cluster bound. We observed electron density that was best fit by a double conformation of the pyruvate-lysine adduct species (Figure S1A,B). In the major conformation (refined occupancy of 0.57), the Schiff base is ligated to the auxiliary cluster. However, in the minor conformation (refined occupancy of 0.43 ), the pyruvate moiety is rotated such that the carboxylate group is facing the Schiff base binding pocket and the methyl group is facing the auxiliary cluster (Figure S1C). We posit that the minor conformation of the Schiff base exists in the $40 \%$ of the molecules that also lack an auxiliary cluster, and is stabilized through side chain interactions (Figure S1D). The remainder of this manuscript will focus on the dominant conformation of the Schiff base species.

Visualization of a $[2 \mathrm{Fe}-3 \mathrm{~S}]$ radical SAM cluster was unexpected given that the protocols used for both anaerobic cluster reconstitution and anaerobic crystallization are the same as those that have been used successfully previously ${ }^{59,60}$ and given that the auxiliary cluster of TYW1 is intact. Thus, the source of the difficulty in observing an intact radical SAM cluster is not obvious. Density for SAM was not apparent in the structure of TYW1, although SAM was present in the crystallization mixture. The absence of SAM in the structure is likely due to cluster disorder. Many unsuccessful attempts were made to obtain a structure of holo-TYW1 with SAM bound (data not shown). Therefore, substrate bound models of TYW1 were achieved by manual docking in Coot.

To model the radical SAM cluster and the bound SAM, the corresponding regions of the MoaA structure (PDB 1TV8) were used as a guide. Protein figures were generated in PyMol, ${ }^{61}$ and electrostatic calculations were performed with the APBS plugin ${ }^{62}$ within PyMol.

Cloning and Purification of C195S and K41A TYW1 Mutants. C195S and K41A TYW1 mutants were created following the Stratagene QuikChange site-directed mutagenesis protocol and pAY613 as a template. To create the K41A mutant, the following primers were used, 5'-CAAAAACTGTTACGCATCAAAATTCTAC$3^{\prime}$ and $5^{\prime}$-GTAGAATTTTGATGCGTAACAGTTTTTG- ${ }^{\prime}$, with the mutated bases shown in bold. To create the C195S mutant, the following primers were used, 5'-CCTACCGTCGCATTTCCGGCGGTAAAAAAGAATAC-3' and 5'-GTATTCTTTTTTACCGCCGGAAATGCGACGGTAGG- ${ }^{\prime}$, with the mutated bases shown in bold. The mutant proteins were expressed and purified as described above for wtTYW1.

Activity Assays of C195S and K41A Variants. The assays were performed in $0.1 \mathrm{M}$ Tris- $\mathrm{HCl}(\mathrm{pH} 8), 0.1 \mathrm{M} \mathrm{KCl}, 4 \mathrm{mM}$ DTT, $2 \mathrm{mM}$ SAM, $2 \mathrm{mM}$ pyruvate, $10 \mathrm{mM}$ sodium dithionite, $1.5 \mathrm{mM}$ methyl viologen, $200 \mu \mathrm{g}$ of yeast tRNA, and $100 \mu \mathrm{M}$ protein. The reactions were incubated at $50{ }^{\circ} \mathrm{C}$ overnight. The RNA was extracted and digested to the nucleoside level as previously described. The resulting nucleotide mixture $(20 \mu \mathrm{L})$ was injected onto a Thermo Vanquish UHPLC interfaced with a Thermo LTQ OrbiTrap XL. The analytes were separated on a Thermo hypersil gold C18 column $(150 \times 2.1$ $\mathrm{mm}^{2}$ ) equilibrated in $50 \mathrm{mM}$ ammonium acetate $(\mathrm{pH} \mathrm{6}$ ) (solution A). Solution B consisted of $40 \%$ acetonitrile (Fisher Optima LC/MS grade). The separation program was as follows with a flow rate of 200 $\mu \mathrm{L} / \mathrm{min}$ : $0-3 \mathrm{~min}, 0 \% \mathrm{~B} ; 3-3.25 \mathrm{~min}, 0-0.2 \% \mathrm{~B} ; 3.25-3.5 \mathrm{~min}, 0.2-$ $0.8 \% \mathrm{~B} ; 3.5-3.75 \mathrm{~min}, 0.8-3.2 \% \mathrm{~B} ; 3.75-4 \mathrm{~min}, 3.2-5 \% \mathrm{~B} ; 4-7 \mathrm{~min}$, 5-25\% B; 7-10 min, 25-50\%; 10-12 min, 50-75\% B; 12-12.1 min, $75-100 \%$ B; $12.1-15 \mathrm{~min}, 100 \%$ B; $15-15.1 \mathrm{~min}, 100-0 \%$ B; $15.1-$ $18 \mathrm{~min}, 0 \% \mathrm{~B}$. The LTQ OrbiTrap XL was operated in positive ion mode with the FT analyzer set to a resolution of 100,000.

Trapping of Schiff Base in TYW1. The assays to trap the Schiff base intermediate were performed in $0.1 \mathrm{M}$ Tris $-\mathrm{HCl}(\mathrm{pH}$ 8.0) buffer containing $0.1 \mathrm{M} \mathrm{KCl}, 4 \mathrm{mM}$ DTT, $2 \mathrm{mM}$ SAM, $10 \mathrm{mM}$ pyruvate (either $1,2,3-{ }^{13} \mathrm{C}_{3}$-pyruvate or $1-{ }^{13} \mathrm{C}_{1}$-pyruvate), $10 \mathrm{mM}$ sodium dithionite, $1.5 \mathrm{mM}$ methyl viologen, $200 \mu \mathrm{g}$ of yeast tRNA, $10 \mathrm{mM}$ sodium cyanoborohydride $\left(\mathrm{NaCNBH}_{3}\right)$ or sodium cyanoborodeuteride $\left(\mathrm{NaCNB}^{2} \mathrm{H}_{3}\right)$ (freshly prepared), and $100 \mu \mathrm{M} \mathrm{C195S-TYW1.} \mathrm{The}$ reactions were incubated for $7 \mathrm{~h}$ in the glovebox at room temperature. Following the incubation, 20 units of trypsin (bovine pancreas) dissolved in $100 \mathrm{mM}$ Tris- $\mathrm{HCl}(\mathrm{pH} 8.0)$ was added to each assay, and assays were incubated at room temperature overnight. The following day, DTT was added to a final concentration of $9.5 \mathrm{mM}$ and assays were incubated for $45 \mathrm{~min}$ at $56{ }^{\circ} \mathrm{C}$. The reactions were cooled to room temperature, 2-iodoacetamide, dissolved in $100 \mathrm{mM}$ ammonium bicarbonate, was added to a final concentration of $23 \mathrm{mM}$, and assays were incubated in the dark at room temperature for $30 \mathrm{~min}$. Trypsin and other large molecules were removed by filtration through a PES $10 \mathrm{~K}$ centrifugal filter, and $80 \mu \mathrm{L}$ of the filtrate was injected onto a Thermo Vanquish UHPLC interfaced with a Thermo LTQ OrbiTrap $\mathrm{XL}$. The analytes were separated on a Thermo hypersil gold C18 column $\left(150 \times 2.1 \mathrm{~mm}^{2}\right)$ equilibrated in $0.1 \%$ TFA (Fisher Optima LC/MS grade) (solution A). Solution B consisted of acetonitrile:0.1\% 


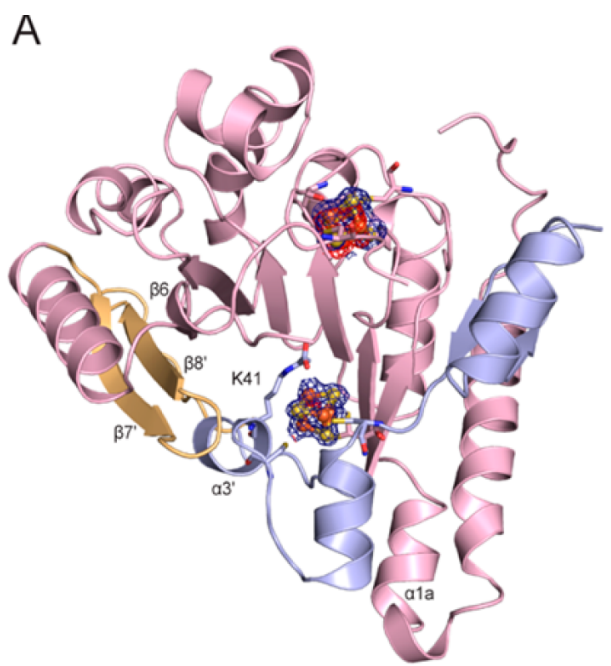

B

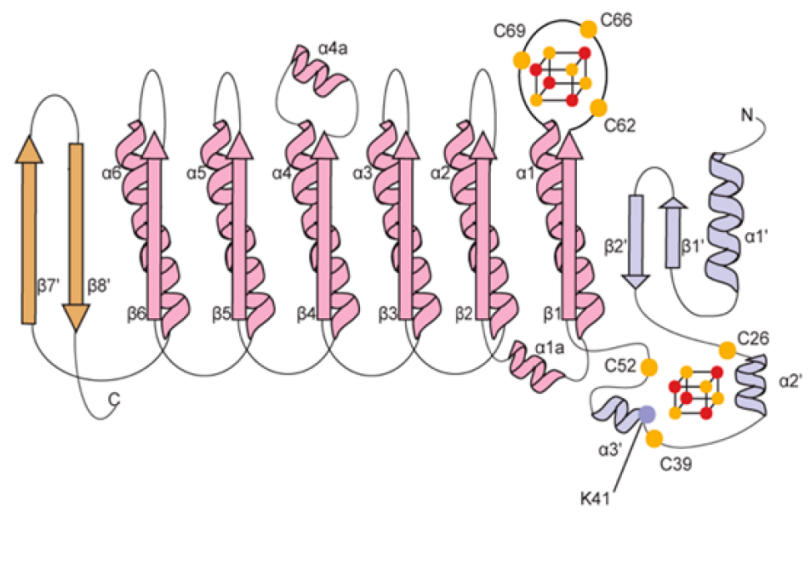

Figure 1. Overall architecture of TYW1. (A) TYW1 adopts a partial $(\beta / \alpha)_{6}$ TIM barrel fold (light pink), which is expanded at both the N-terminus (light blue) and the C-terminus (light orange). The radical SAM cluster and auxiliary $[4 \mathrm{Fe}-4 \mathrm{~S}]$ cluster are shown as spheres (iron in orange and sulfur in yellow) surrounded by $2 \mathrm{Fo}-\mathrm{Fc}$ electron density contoured at $+1 \sigma$ (blue). When the radical SAM cluster is refined as a [4Fe-4S] cluster, negative difference density $(-3 \sigma$, red) is visible, suggesting either incomplete assembly of the cluster or partial cluster degradation. The location of K41 is also shown. (B) Topology diagram of the overall structure of TYW1, colored as in part A. The cysteine ligands to the clusters are shown as yellow spheres. The position of $\mathrm{K} 41$ is represented as a blue sphere.

TFA (Fisher Optima LC/MS grade). The separation program was as follows with a flow rate of $200 \mu \mathrm{L} / \mathrm{min}: 0-1 \mathrm{~min}, 0 \% \mathrm{~B} ; 1-6.5 \mathrm{~min}$, $0-30 \% \mathrm{~B}$; $6.5-6.6 \mathrm{~min}, 30-100 \% \mathrm{~B} ; 6.6-9.6 \mathrm{~min}, 100 \% \mathrm{~B} ; 9.6-9.7$ min, $100-0 \%$ B; $9.7-12.7 \mathrm{~min}, 0 \%$ B. The LTQ OrbiTrap XL was operated in positive ion mode with the FT analyzer set to a resolution of 100,000 .

Controls to determine which components were required for the trapping of a Schiff base were carried out as described above in the presence of $1,2,3-{ }^{13} \mathrm{C}_{3}$-pyruvate and either $\mathrm{NaCNBH}_{3}$ or $\mathrm{NaCNB}^{2} \mathrm{H}_{3}$ in the absence of one of the following components, SAM, sodium dithionite, or tRNA. The resulting protein was analyzed as described above.

The Schiff base trapping assay was repeated with wtTYW1 to ensure that the wild type protein formed the same adduct as the C195S protein. The assay was repeated as described above using wtTYW1 instead of C195S-TYW1.

\section{RESULTS}

Overall Architecture of holo-TYW1. To investigate the molecular architecture of holo-TYW1, a structure of anaerobically purified and reconstituted TYW1 from Methanocaldococcus jannaschii was solved to $1.6 \AA$ resolution (Figure 1). TYW1 crystallizes as a functional monomer with the structural core adopting a partial $(\beta / \alpha)_{6}$ TIM barrel, the radical SAM core fold found in most members of the radical SAM superfamily. ${ }^{40,42,50,51,63-72}$ This core fold includes a loop that follows $\beta 1$ and provides the three cysteines, C62, C66, and C69, of the $\mathrm{CX}_{3} \mathrm{CX} \phi \mathrm{C}$ motif for binding the canonical radical SAM cluster (where $\phi$ is a conserved aromatic residue). ${ }^{73}$ In TYW1, the core fold is extended by the addition of $\mathrm{N}$ - and C-terminal extensions, which flank either side of the partial TIM barrel architecture (Figure 1). The $\mathrm{N}$-terminal extension begins with $\alpha 1^{\prime}$, which folds into an antiparallel $\beta$-hairpin $\left(\beta 1^{\prime}\right.$ and $\left.\beta 2^{\prime}\right)$ that extends the inner face of the partial barrel. $\beta 2^{\prime}$ is followed by two $\alpha$-helices, $\alpha 2^{\prime}$ and $\alpha 3^{\prime}$, which sit below the base of the $\mathrm{N}$ terminal region of the radical SAM domain, creating a binding site for a second, or auxiliary, iron-sulfur cluster. On the other side of the radical SAM domain, the C-terminal extension folds into a nonconsecutive antiparallel $\beta$-sheet, $\beta 7^{\prime}$ and $\beta 8^{\prime}$, where $\beta 8^{\prime}$ is found adjacent to $\beta 6$ (of the radical SAM domain). The
C-terminal extension expands the inner face of the active site, and with $\alpha 3^{\prime}$ of the $\mathrm{N}$-terminal extension helping to seal off the bottom of the barrel.

In this structure, we observe one intact and one partial $[4 \mathrm{Fe}-4 \mathrm{~S}]$ cluster. The canonical $[4 \mathrm{Fe}-4 \mathrm{~S}]$ radical SAM cluster is not intact and is best accounted for by a $[2 \mathrm{Fe}-3 \mathrm{~S}]$ cluster (Figure 1A) with a water molecule as the fourth ligand, suggesting either cluster degradation or incomplete cluster reconstitution. In contrast, the auxiliary cluster is an intact $[4 \mathrm{Fe}-4 \mathrm{~S}]$ cluster coordinated by three conserved cysteines, C26, C39, and C52 (Figures 1A,B and 2A).

Two apo structures of TYW1 from Methanocaldococcus jannaschii (apo-MjTYW1) ${ }^{50}$ and Pyrococcus horikoshii (apoPhTYW1 $)^{51}$ have been previously reported to 2.4 and $2.2 \AA$ resolution, respectively. These two structures are very similar to our MjTYW1 structure, with a rmsd of $0.56 \AA$ for apoMjTYW1 and $0.94 \AA$ for apo-PhTYW1 (calculated by alignment of 222 out of 280 and 234 out of 325 alpha carbons, respectively, using $\mathrm{PyMol}^{61}$ ). A key difference between these structures and ours is the increased iron-sulfur cluster content in our structure, but the previous structures did correctly predict the locations of the cluster-binding sites on the basis of the clustering of conserved Cys residues. ${ }^{50,51}$ Interestingly, outside of the other TYW1 structures, the closest structural homologue with a $Z$-score of 15 and a rmsd of $3.8 \AA$ is $\mathrm{RlmN}$, a radical SAM enzyme involved in the methylation of rRNA and recently discovered to also methylate tRNA. ${ }^{68,74}$ Additional structurally similar enzymes are pyruvate formate lyase activating enzyme (PFL-AE, Z-score of 14.5 and rmsd of 3.0 $\AA$ ), viperin ( $Z$-score 12.4 and rmsd of $3.5 \AA$ ), MoaA (Z-score 12.0 and rmsd of $3.5 \AA$ ), and QueE ( $Z$-score of 11.8 and rmsd of $3.8 \AA$ ).

Visualization of a Schiff Base Intermediate in Crystallo. Sequence analysis correctly predicted incomplete Cys ligation of the auxiliary cluster; ${ }^{35,50}$ only three cysteine residues are conserved (C26, C39, and C52) outside of the canonical radical SAM cluster binding $\mathrm{CX}_{3} \mathrm{CX} \phi \mathrm{C}$ motif, and we find that only these three conserved cysteine residues 


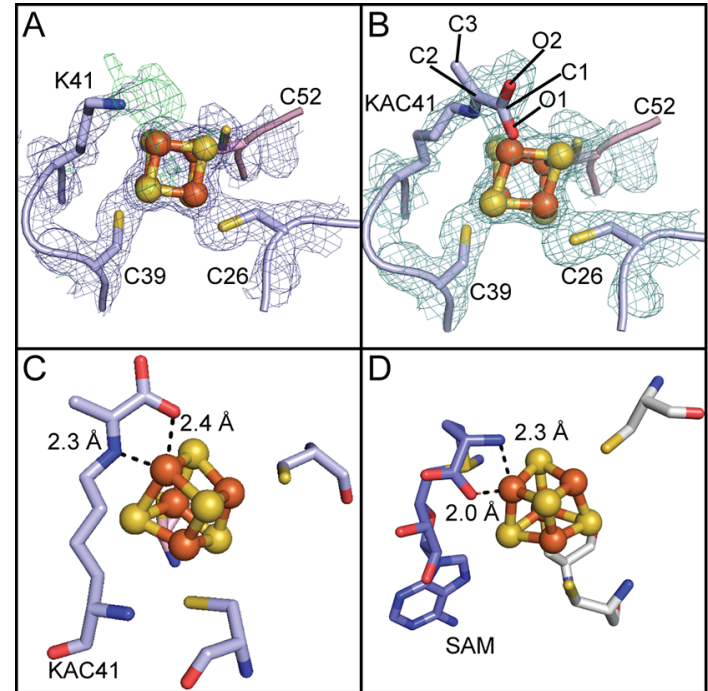

Figure 2. A Schiff base intermediate in TYW1 is visualized. (A) An intact $[4 \mathrm{Fe}-4 \mathrm{~S}]$ auxiliary cluster is shown surrounded by $2 \mathrm{Fo}-\mathrm{Fc}$ electron density, contoured at $1 \sigma$ (blue). Three cysteine ligands, C26, C39, and C52, bind the auxiliary cluster, producing a site differentiated iron ion, which is in close proximity to K41. A positive difference density (green) contoured at $+3 \sigma$ is shown extending from Nz of K41 to the unique iron. (B) To account for difference electron density, a Schiff base between K41 and the substrate pyruvate (KAC41) was modeled and refined. A $2 \mathrm{Fo}-\mathrm{Fc}$ omit density map (cyan) contoured at $1 \sigma$ is shown for the auxiliary cluster, cysteine ligands, and covalent adduct. (C) The Schiff base intermediate, KAC41, ligates the unique iron of the auxiliary cluster of TYW1 in a bidentate fashion through interactions with the $\mathrm{Nz}$ atom (blue) and a carboxylic oxygen (red). (D) SAM ligating the unique iron of the SAM cluster in MoaA (PDB 1TV8), utilizing the amino nitrogen (blue) and a carboxylic oxygen (red). All residues are shown as sticks.

coordinate this auxiliary $[4 \mathrm{Fe}-4 \mathrm{~S}]$ cluster (Figure 2A,B). In contrast to predictions, however, there is not an open coordination site on the auxiliary cluster. Instead, we find the catalytically essential residue, $\mathrm{K} 41,{ }^{50}$ in close proximity $(\sim 2.8$ $\AA$ ) to the unique iron of the auxiliary cluster (Figure $2 \mathrm{~A}$ ). During iterative rounds of refinement and model building, positive difference density extending from the $\mathrm{Nz}$ of K41 toward the unique iron of the auxiliary cluster appeared (Figure 2A). Guided by this difference density, we modeled in and refined the Schiff base intermediate predicted to form ${ }^{32,33}$ between a lysine residue and the pyruvate substrate during catalysis. ${ }^{32,33}$ We found that a pyruvate-lysine adduct accounts well for the density (Figure 2B). It must be noted that the density observed for the adduct can also accommodate a reduced Schiff base, and therefore, we cannot rule out the possibility that the species observed is an amine rather than an imine. Regardless, this covalent Schiff base adduct places the oxygen of the carboxylic acid of pyruvate and the $\mathrm{Nz}$ of lysine about 2.4 and $2.3 \AA$ away from the unique iron of the auxiliary cluster, respectively, creating a bidentate ligation reminiscent of SAM binding to the radical SAM clusters of members of the superfamily $^{40,43,59,60,67,72,75-78}$ (Figure 2C,D).

In addition to interactions with the unique iron, the Schiff base is stabilized in the active site through water hydrogen bonds (Figure 3A). At a distance of 2.5 and $3.0 \AA$, a water molecule bound by Q54 and S134 provides contacts to the carboxylic group of the pyruvate-derived portion of the Schiff base. Whereas stacking interactions from F160 help orient the

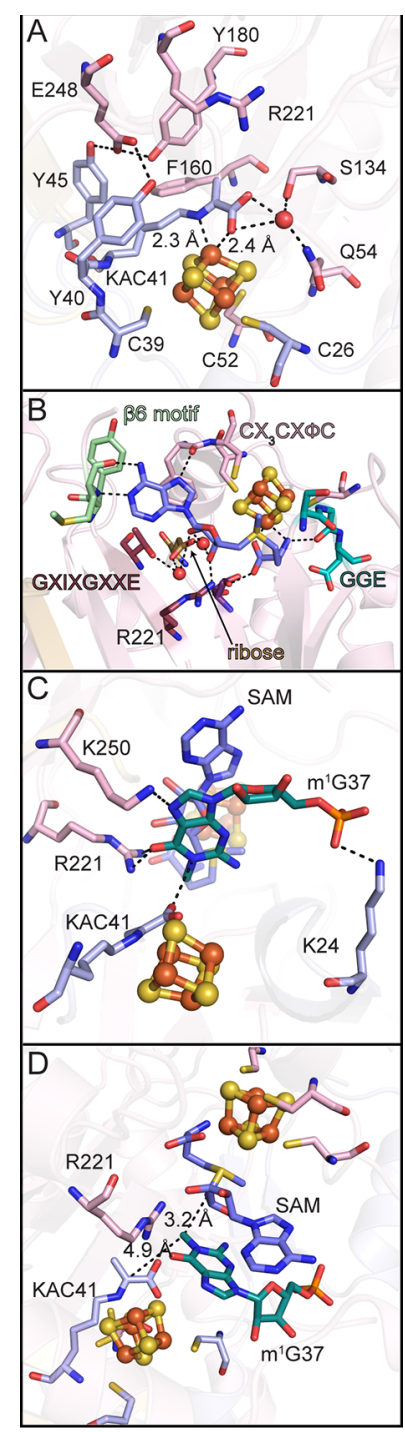

Figure 3. TYW1 active site structure and models. (A) The binding pocket of KAC41 is shown, with interactions represented as dashed lines. (B) SAM molecule (slate) modeled in the active site with dashed lines indicating potential hydrogen bonds. The positions of classic SAM radical motifs are labeled. (C) $\mathrm{m}^{1} \mathrm{G}$ (teal) modeled into the active site with potential interacting residues shown as sticks. (D) The $\mathrm{m}^{1} \mathrm{G}$ (teal) modeled structure from panel $\mathrm{C}$ is shown in a different orientation with the dashed lines highlighting the distances between the sites of hydrogen atom abstraction.

C3 methyl of the pyruvate-lysine adduct in the active site, the inner face of the Schiff base binding site is made up of an intricate hydrogen bonding network between highly conserved residues, Y40, Y45, Y180, and E248, from the N-terminal extension and the radical SAM core. These interactions (Figure $3 \mathrm{~A}$ ) serve to orient the adduct species at the base of the active site with $\mathrm{C} 2$ of pyruvate, the site of radical attack by the $\mathrm{m}^{1} \mathrm{G}$ substrate radical, $12.6 \AA$ away from the radical SAM cluster.

SAM Binding Motifs Appear to Be Conserved. We modeled the missing atoms of the radical SAM cluster using the positions of the cluster atoms that we could observe and modeled SAM binding to the cluster using the structure of MoaA (PDB 1TV8) as a guide (Figure S2). In particular, SAM was positioned such that its amino group and its carboxylic group were 2.3 and $2.0 \AA$ from the unique iron, respectively. SAM was also positioned in a catalytically competent 
orientation with the $S$ atom poised $3.2 \AA$ from the unique iron. We find that, when SAM is positioned in this classic orientation with respect to the radical SAM cluster, SAM can make the traditional interactions with the SAM-binding motifs. ${ }^{75,76,79}$ For example, a carbonyl from the "GGE" motif, $\mathrm{S}_{136} \mathrm{G}_{137} \mathrm{E}_{138}$ in TWY1, is available to hydrogen bond to the amide of SAM, and D184 (ribose motif) and R221 are positioned to interact with the ribose hydroxyl groups of SAM either through a water molecule or hydrogen bond, respectively (Figure $3 \mathrm{~B}$ ). Residues T223 (GXIXGXXE motif) and $\mathrm{F} 68$ ( $\phi$ in the $\mathrm{CX}_{3} \mathrm{CX} \phi \mathrm{C}$ motif) are found in close proximity to the adenine moiety of modeled SAM and can provide hydrophobic interactions to orient the adenine ring. In addition, backbone atoms are positioned to make classic interactions, M251 ( $\beta_{6}$ motif) and F68 $\left(\mathrm{CX}_{3} \mathrm{CX} \phi \mathrm{C}\right.$ motif), to the N1, N6 exocyclic amine and N7 of the adenine moiety (Figure $3 \mathrm{~B}$ ).

A Positive Electrostatic Surface near the Active Site Suggests the Location of the tRNA Binding Site. The nucleotide modified by TYW $1, \mathrm{~m}^{1} \mathrm{G} 37$, is part of the ACSL of tRNA $^{\text {Phe }}$, which when bound to its modifying enzyme is expected to adopt a tRNA bulge conformation that has $\mathrm{m}^{1} \mathrm{G} 37$ flipped out of the loop. ${ }^{74,80}$ Due to its negatively charged phosphate backbone, the ACSL should bind a positively charged site on the protein. Electrostatic calculations (Figure 4)

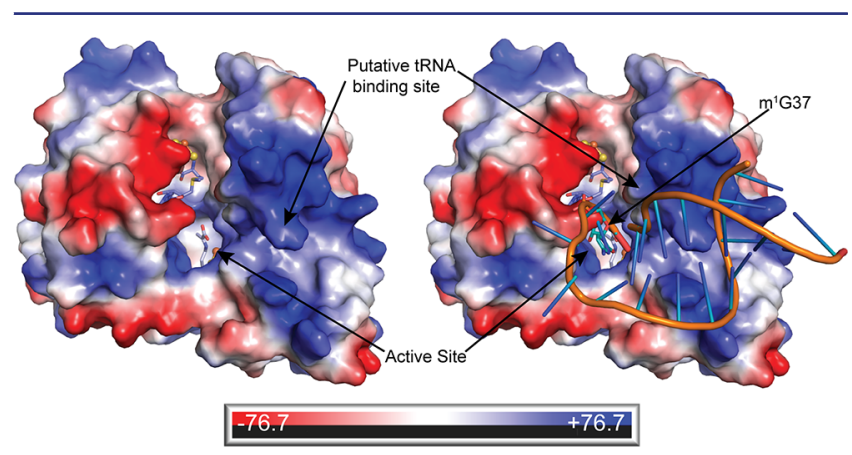

Figure 4. Electrostatic surface of TYW1. The surface of TYW1 is colored on the basis of its electrostatic properties with positively charged areas in blue and negatively charged areas in red. A path of positive electrostatic surface leads from the active site to a putative binding site for $\mathrm{tRNA}^{\text {Phe }}$. SAM ( $\mathrm{C}$ in slate) and KAC41 ( $\mathrm{C}$ in light blue) are shown in sticks. A model of a 20-base-pair tRNA anticodon stem loop (PDB 1EHZ in orange) is shown against this surface. The site of tRNA base modification, $\mathrm{m}^{1} \mathrm{G} 37$ ( $\mathrm{C}$ in teal), is shown as sticks in the active site.

show a large region of positive electrostatic charge that leads from the active site cavity to the tip of the $\mathrm{N}$-terminal extension near $\alpha 3^{\prime}$ and $\alpha 1$ a (Figure 4). Modeling suggests that this patch of positive charge is appropriately the correct size for a 20-basepair ACSL (Figure 4). In this model, the $\mathrm{m}^{1} \mathrm{G} 37$ sits on top of the active site with the rest of the ACSL extended along the positively charged protein surface (Figure 4). The active site of TYW1 is solvent exposed in the absence of nucleotide substrate, but the binding of a tRNA ${ }^{\text {Phe }}$ molecule to TYW1 would be expected to close off the active site, making it less accessible to solvent.

There is a space in between SAM and the Schiff base in the active site cavity that is a suitable size for a $\mathrm{m}^{1} \mathrm{G}$ binding site (Figure 3C,D). Modeling $\mathrm{m}^{1} \mathrm{G}$ into this putative binding site positions the N1-methyl group of $\mathrm{m}^{1} \mathrm{G}$ (the site of hydrogen atom abstraction by dAdo•) $3.2 \AA$ away from the C-5' of SAM (Figure 3D). The N1-methyl group is also $4.9 \AA$ from the $\mathrm{C} 2$ of the pyruvate-derived portion of the Schiff base intermediate (Figure 3D). In this location, the base of $\mathrm{m}^{1} \mathrm{G}$ would be capable of making $\pi-\pi$ stacking interactions with the adenine ring of SAM and forming hydrogen bonds $(\sim 2.4 \AA)$ between O6 and R221 and ( 2.9 $\AA$ ) between N7 and K250 (Figure 3C). The phosphate group could be stabilized by hydrogen bonding interactions with K24, distance modeled at $2.6 \AA$ (Figure 3C).

In Vitro Activity of C195S and K41A TYW1 Mutants. K41 has been shown previously to be essential in vivo, ${ }^{50}$ and here we wanted to verify that a K41A variant protein is unable to produce imG-14 in vitro. As a control, we also prepared a C195S TYW1 variant. C195 is adjacent to the radical SAM cluster but is not a direct cluster ligand. The extracted ion chromatogram at $m / z 322\left(\mathrm{imG}-14\left[\mathrm{M}+\mathrm{H}^{+}\right]\right.$) obtained when C195S TYW1 (red), wild type TYW1 (black), and K41A TYW1 (blue) are incubated in the presence of tRNA, reductant, SAM, and pyruvate is shown in Figure 5. There is

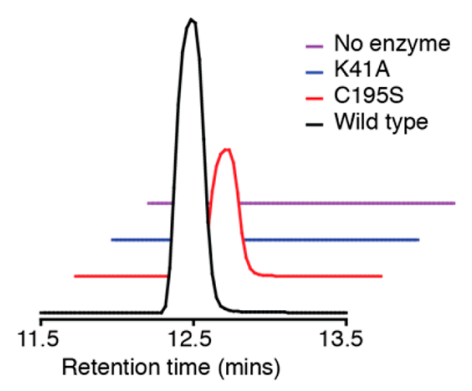

Figure 5. Activity of TYW1 with RNA. The extracted ion chromatogram from $\mathrm{m} / \mathrm{z} 322.1$ to 322.12 showing that imG-14 forms in the presence of wildtype TYW1 and the C195S variant but not with K41A or when TYW1 is not included in the assay.

a peak present in both the wild type and C195S samples that is not present in the negative control (no enzyme) or in the K41A sample that corresponds to imG-14. Therefore, at least under the conditions of the assay, C195S variant is catalytically active and $\mathrm{K} 41 \mathrm{~A}$ is not active. This finding supports the importance of K41 in catalysis. The C195S variant is used in the subsequent Schiff base trapping experiments.

In Vitro Trapping of a Schiff Base Intermediate Using C195S-TYW1. To unambiguously demonstrate formation of a Schiff base between TYW1 and pyruvate, C195S-TYW1 was incubated with $\mathrm{NaCNBH}_{3}$ and $\mathrm{NaCNB}^{2} \mathrm{H}_{3}$ in the presence of SAM, reductant, and substrate. Reactions were treated with iodoacetamide prior to tryptic digestion to ensure that oxidation of cysteines did not occur. The shortest tryptic fragment of TYW1 containing a pyruvate-modified K41 would be NCYK, where $K$ denotes the modified K41 and $C$ denotes a carbamidomethylated cysteine residue. Since a modified $K$ at the cleavage site for trypsin may lead to a missed cleavage, we also considered that the shortest observable fragment would be NCYKSK. The fragment NCYK would have $m / z 584.2497$ [M $+\mathrm{H}^{+}$, while modification of the lysine, $\mathrm{NCYK}$, would shift the mass of the peptide to $m / z 656.2708\left[\mathrm{M}+\mathrm{H}^{+}\right]$. The fragment NCYKSK peptide should have $m / z$ of $799.3767\left[\mathrm{M}+\mathrm{H}^{+}\right]$, whereas a pyruvate-modified lysine, NCYKSK, would shift the mass to $m / z 871.3978\left[\mathrm{M}+\mathrm{H}^{+}\right]$.

The ability of TYW1 to form a Schiff base with pyruvate was investigated by incubating the enzyme under anaerobic conditions in a mixture that contained all components of the assay, including pyruvate, yeast tRNA, methyl viologen, dithionite, and SAM. In addition, $\mathrm{NaCNBH}_{3}$ was also added 
in the incubations to stabilize the Schiff base that forms by reduction. The samples were digested with trypsin, the cysteine residues alkylated, and the resulting fragments subjected to LCMS analysis, following the incubations. The extracted ion chromatograms (Figure S3) reveal a peak at $\mathrm{m} / z$ 871, corresponding to NCYKSK, as well as a peak at $m / z$ 584.2497, corresponding to NCYK. These results were encouraging, as they suggested that the $\mathrm{K}$ could be modified; however, we could not eliminate the possibility that the modified $\mathrm{K}$ was present in the purified enzyme.

To determine the source of the pyruvate appended to K41, identical incubations were carried out with $1,2,3-{ }^{13} \mathrm{C}_{3}$-pyruvate. The resulting extracted ion chromatograms (Figure S4) reveal peaks at $m / z 874$, which would be expected for a NCYKSK fragment where the $1,2,3-{ }^{13} \mathrm{C}_{3}$-pyruvate is present. Interestingly, we also observe a significant peak at $\mathrm{m} / z$ 871, which corresponds to unlabeled pyruvate appending K41. This peak likely results from pyruvate that is adventitiously bound to the enzyme through K41. In fact, we point out that the structure of the pyruvate-modified K41 reported above was solved with protein that had never been incubated with pyruvate in vitro, and was likely purified with the Schiff base that had formed during protein production in vivo, or during the purification and reconstitution of the protein under reducing conditions.

To further confirm that the peak at $\mathrm{m} / z 874$ corresponds to NCYKSK, which is obtained by pyruvate modification and subsequent reduction with $\mathrm{NaCNBH}_{3}$, we repeated the experiment with $\mathrm{NaCNB}^{2} \mathrm{H}_{3}$. In this experiment we would expect that the peak at $m / z 874$ that is observed with $1,2,3-{ }^{13} \mathrm{C}_{3}$-pyruvate would shift to 875 in the presence of $\mathrm{NaCNB}^{2} \mathrm{H}_{3}$. Indeed, as predicted, when TYW1 was incubated in the presence of cyanoborohydride, the $\mathrm{m} / z$ peak for NCYKSK shifted from 874.4085 to 875.4156 , which is within $1 \mathrm{ppm}$ of the theoretical mass of the peptide containing three ${ }^{13} \mathrm{C}$ and one ${ }^{2} \mathrm{H}$ atoms (Figure $6 \mathrm{~A}$ and $\mathrm{B}$ ). These data unambiguously show that pyruvate can modify K41 to a Schiff base.

In the experiments with the $\mathrm{NaCNB}^{2} \mathrm{H}_{3}$ and $1,2,3-{ }^{13} \mathrm{C}_{3}$ pyruvate, as with the experiments with unlabeled reductant, we also observe a peak at 871.399 corresponding to NCYKSK that does not undergo reduction. This result suggests that the pool

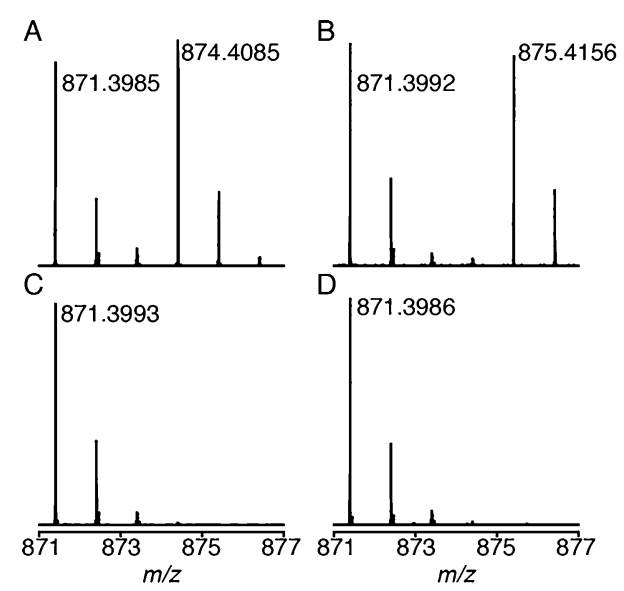

Figure 6. Mass spectrum of a tryptic fragment of TYW1. TYW1 incubated with (A) $1,2,3-{ }^{13} \mathrm{C}_{3}$ pyruvate in the presence of $\mathrm{NaCNBH}_{3}$, (B) $1,2,3-{ }^{13} \mathrm{C}_{3}$ pyruvate in the presence of $\mathrm{NaCNB}^{2} \mathrm{H}_{3}$, (C) no pyruvate in the presence of $\mathrm{NaCNBH}_{3}$, and (D) no pyruvate in the presence of $\mathrm{NaCNB}^{2} \mathrm{H}_{3}$. of pyruvate-modified K41 that we observe is already reduced in the protein. To probe this further, we repeated the experiment in the absence of added pyruvate (Figure 6C and D). Indeed, the peak at 871.399 does not shift when $\mathrm{NaCNB}^{2} \mathrm{H}_{3}$ is used, confirming the presence of modified $\mathrm{K} 41$ in the sample. We cannot eliminate the possibility that the reduction of this pool occurs in the course of the incubation, as the structural data do not clearly distinguish between an imine and an amine.

To determine which reaction components were required for the Schiff base to form, a series of control reactions were set up with TYW1 in the presence of $1,2,3-{ }^{13} \mathrm{C}_{3}$-pyruvate and either $\mathrm{NaCNBH}_{3}$ or $\mathrm{NaCNB}^{2} \mathrm{H}_{3}$ (Figure S5). The controls show that SAM, dithionite, or tRNA are not required, as the peak at $\mathrm{m} / z$ $874.4085 \pm 1 \mathrm{ppm}$ (with $\mathrm{NaCNBH}_{3}$ ) or $\mathrm{m} / z 875.4148 \pm 1$ ppm (with $\mathrm{NaCNB}^{2} \mathrm{H}_{3}$ ) is present in all of the samples. Therefore, the formation of the Schiff base is not dependent upon the presence of the tRNA or the oxidation state of the cluster, which is in agreement with previously published spectroscopic studies that show changes in the environment of the auxiliary cluster in the presence of pyruvate in the absence of SAM or reductants. ${ }^{35,52}$

\section{DISCUSSION}

The mechanism by which TYW1 catalyzes the addition of two carbon atoms from pyruvate to extend the ring of $\mathrm{m}^{1} \mathrm{G} 37$, forming the characteristic imidazopurine of the wyosine bases found in tRNA ${ }^{\text {Phe }}$, has been disputed. ${ }^{32-36,52}$ Although both mechanistic paradigms suggest a role for the auxiliary cluster in activating pyruvate, one suggests a more intimate interaction between TYW1 and pyruvate, which is mediated by a Schiff base linkage. Herein, we present biochemical and structural evidence to support a role for a Schiff base in the reaction catalyzed by TYW1.

Our structure presents the first snapshot of the active site of TYW1 with iron sulfur clusters bound. This structure reveals electron density for an auxiliary $[4 \mathrm{Fe}-4 \mathrm{~S}]$ cluster coordinated by the three conserved cysteines, confirming the results of a previous EPR and Mossbauer study. As predicted, the conserved and catalytically important K41 is found in close proximity to the unique iron of the auxiliary cluster. K41 has been shown previously to be essential for in vivo activity; ${ }^{50}$ the recombinant $\mathrm{K} 41 \mathrm{~A}$ variant is shown here to be catalytically inactive, further emphasizing its essential role. We observe electron density consistent with pyruvate forming a Schiff base intermediate with K41 and find that the adduct is within hydrogen bonding distance of the cluster, consistent with earlier EPR and Mossbauer studies. ${ }^{35,52}$ In addition, the chemical in vitro trapping of a pyruvate-lysine adduct using pyruvate, $1,2,3-{ }^{13} \mathrm{C}_{3}$-pyruvate, and either $\mathrm{NaCNBH}_{3}$ or $\mathrm{NaCNB}^{2} \mathrm{H}_{3}$ further confirms that TYW1 is able to form a Schiff base intermediate between pyruvate and K41, which is in line with mechanism 1 in Scheme 2.

A mechanistic paradigm for TYW1 that is consistent with all structural, biochemical, and spectroscopic evidence to date is shown in Scheme 3. A Schiff base between K41 and pyruvate is proposed to precede the reductive cleavage of SAM and the subsequent hydrogen abstraction from $\mathrm{m}^{1} \mathrm{G}$. The resulting $\mathrm{m}^{1} \mathrm{G}$ methylene radical can attack the $\mathrm{C} 2$ of the cluster-bound Schiff base, forming a new $\mathrm{C}-\mathrm{C}$ bond and leading to a subsequent decarboxylation.

Although the fate of $\mathrm{C} 1$ of pyruvate remains to be established, the ligation of the Schiff base to the cluster sets up the adduct for one electron oxidation by the auxiliary cluster, 
Scheme 3. Mechanism 1 Revised to Highlight Structural Features of the TYW1 Active Site

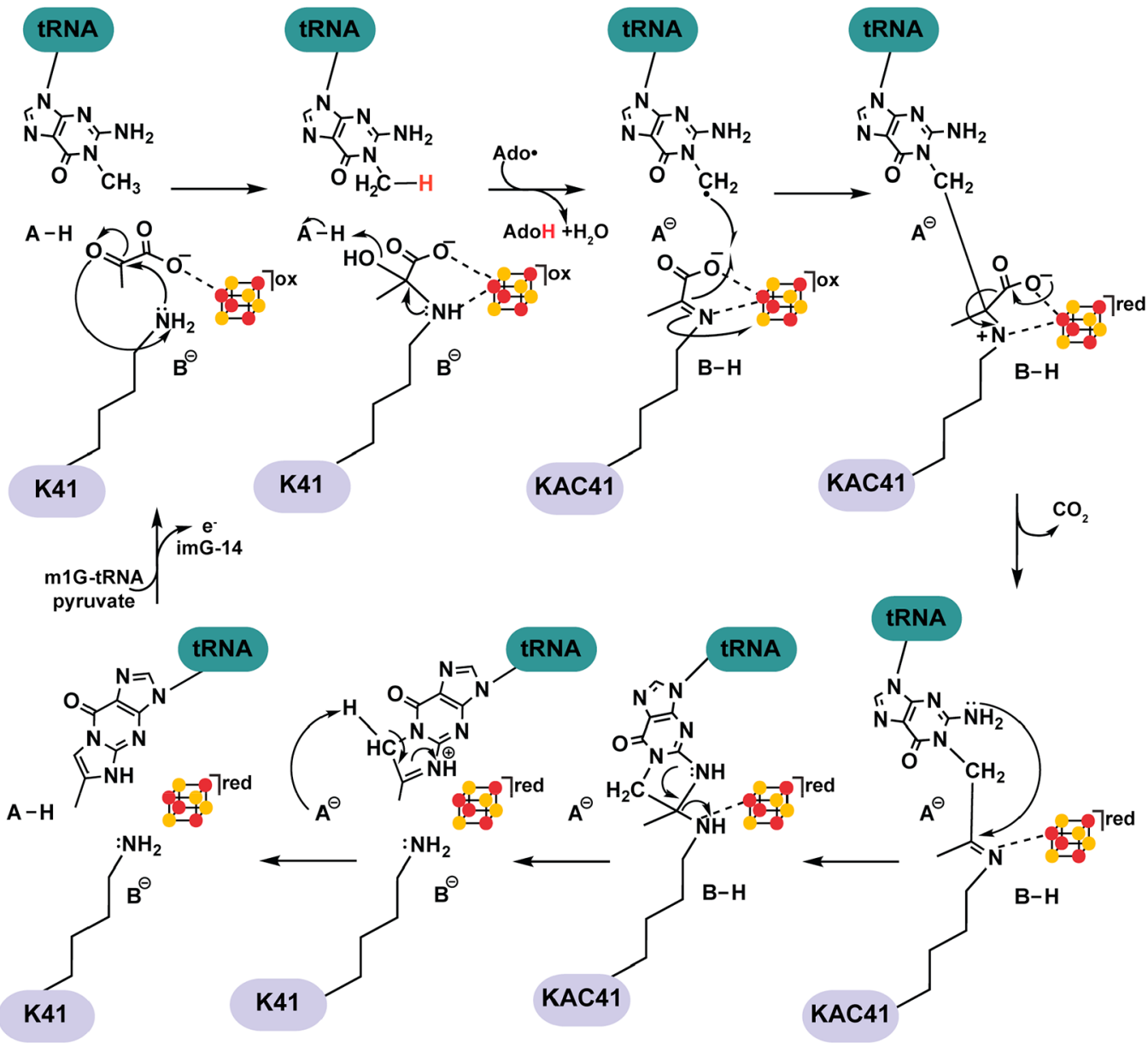

which would lead immediately to decarboxylation to carbon dioxide. Reduction of the cluster and concomitant formation of carbon dioxide would place the cluster in the +1 oxidation state, which is in agreement with previous Mossbauer and EPR studies. $^{35,52}$ For subsequent turnover cycles, flavodoxin could reoxidize the auxiliary cluster and potentially deliver the electron back to the radical SAM cluster, preparing it for the next round of catalysis, as has been observed in AtsB and anSMEcpe. $^{81}$

Visualization of a Schiff base intermediate raises the question of why TYW1 needs both a Schiff base intermediate and an iron sulfur cluster in wyosine base formation, when either in theory is sufficient to perform the requisite chemistry; both can act as an electron sink during catalysis, and both can bind and appropriately orient the substrate. Hints may be found in revisiting the roles of Schiff base intermediates in biochemistry and the structure of TYW1. Schiff bases are used enzymatically, producing a highly reactive imine intermediate. As in other radical SAM enzymes, the core of TYW1's structural architecture is comprised of a partial $(\beta / \alpha)_{6}$ TIM barrel which buries the active site within the inner face of the barrel. This enclosure of the active site serves to sequester the reactive radical species produced during catalysis and decrease off pathway interactions, a strategy used by both radical SAM enzymes and cobalamin dependent enzymes. In TYW1, the active site cavity is largely solvent exposed but would be sealed off with binding of the bulky tRNA substrate. The active site cavity as well as the surface leading from the active site cavity is largely positively charged, and tRNA is predicted to bind with the anticodon stem loop making contact with this positive patch of protein surface, orienting the anticodon loop to sit on top of the active site. Binding of the tRNA will not only effectively seclude the active site from solvent, but it will also impede the diffusion of substrates into the active site. No other channel for substrate entry into TYW1 has been found, and it is possible that all three substrates, SAM, pyruvate, and tRNA ${ }^{\text {Phe }}$, access the active site through the opening observed in the structure. This active site architecture imposes an order of binding on the substrates, as the negatively charged pyruvate molecule and SAM molecule will not be able to enter the active site once tRNA is bound. Taking this idea into consideration, as well as that TYW1 is purified with some reduced Schiff base, the Schiff base in TYW1, in addition to potentially orienting the pyruvate for chemistry, could play a role in tethering pyruvate to the open active site that exists in the absence of the tRNA, priming it for catalysis once the other substrates bind. Therefore, the Schiff base may be playing a complex role by directing binding, orientation, and catalysis in TYW1.

The work presented here strongly supports a mechanistic paradigm where a Schiff base plays a central role in activating the pyruvate for catalysis (Scheme 3). It remains to be seen if the cluster plays a role in resolving the radical intermediate hypothesized to be formed and exist on $\mathrm{C} 1$ during this transformation. Identification of the side product that results from $\mathrm{C} 1$ (carbon dioxide or formate) will be highly informative in this regard. 


\section{CONCLUSION}

Radical SAM enzymes are a treasure trove of interesting chemical reactivity and can proceed through a wide variety of mechanisms to facilitate challenging transformations. Our understanding of the roles of additional cofactors in radical SAM chemistry has been hazy at best, with most additional cofactors having no concrete roles assigned to them. For auxiliary $[4 \mathrm{Fe}-4 \mathrm{~S}]$ clusters, the proposed roles include substrate binding and electron transport. In the biochemical and structural work presented here, we provide support for a Schiff base intermediate in the catalytic mechanism of TYW1. TYW1 is therefore emerging as a member of a subset of radical SAM enzymes that, in addition to employing radical mechanisms to activate their substrates, they also utilize covalent ones.

\section{ASSOCIATED CONTENT}

\section{S Supporting Information}

The Supporting Information is available free of charge on the ACS Publications website at DOI: 10.1021/jacs.8b01493.

Figures S1-S5 showing double conformations of pyruvate-lysine adduct in TYW1, SAM binding motifs of MoaA and TYW1, extracted ion chromatograms of all observable tryptic peptides bearing Lys41, extracted ion chromatogram of the Schiff base intermediate, and mass spectrum of the Schiff base intermediate and Table S1 showing TYW1 data and refinement statistics (PDF)

\section{AUTHOR INFORMATION}

\section{Corresponding Authors}

*vahe@chem.utah.edu

*cdrennan@mit.edu

\section{ORCID $\odot$}

Catherine L. Drennan: 0000-0001-5486-2755

Vahe Bandarian: 0000-0003-2302-0277

\section{Author Contributions}

${ }^{\perp}$ T.A.J.G., A.P.Y.: Co-first authors. These authors contributed equally.

\section{Notes}

The authors declare no competing financial interest.

\section{ACKNOWLEDGMENTS}

This research was supported by the National Science Foundation Graduate Research Fellowship under Grant No. 1122374 (awarded to T.A.J.G.) and a National Institute of General Medical Sciences of the National Institute of Health grant R01 GM72623 (awarded to V.B). C.L.D. is a Howard Hughes Medical Institute Investigator. This work is based upon research conducted at the Northeastern Collaborative Access Team beamlines, which are funded by the National Institute of General Medical Sciences from the National Institutes of Health (P41 GM103403). The Pilatus 6M detector on 24-ID-C beamline is funded by a NIH-ORIP HEI grant ( $\mathrm{S} 10$ RR029205). This research used resources of the Advanced Photon Source, a U.S. Department of Energy (DOE) Office of Science User Facility operated for the DOE Office of Science by Argonne National Laboratory under Contract No. DEAC02-06CH11357.

\section{REFERENCES}

(1) Machnicka, M. A.; Milanowska, K.; Osman Oglou, O.; Purta, E.; Kurkowska, M.; Olchowik, A.; Januszewski, W.; Kalinowski, S.; DuninHorkawicz, S.; Rother, K. M.; Helm, M.; Bujnicki, J. M.; Grosjean, H. Nucleic Acids Res. 2013, 41 (D1), D262.

(2) Cantara, W. A.; Crain, P. F.; Rozenski, J.; McCloskey, J. A.; Harris, K. A.; Zhang, X.; Vendeix, F. A. P.; Fabris, D.; Agris, P. F. Nucleic Acids Res. 2011, 39, D195.

(3) Zallot, R.; Ross, R.; Chen, W.-H.; Bruner, S. D.; Limbach, P. A.; de Crécy-Lagard, V. ACS Chem. Biol. 2017, 12 (3), 844.

(4) Miles, Z. D.; McCarty, R. M.; Molnar, G.; Bandarian, V. Proc. Natl. Acad. Sci. U. S. A. 2011, 108 (18), 7368.

(5) McCarty, R. M.; Bandarian, V. Bioorg. Chem. 2012, 43 (C), 15.

(6) Bandarian, V.; Drennan, C. L. Curr. Opin. Struct. Biol. 2015, 35, 116

(7) Iwata-Reuyl, D. Bioorg. Chem. 2003, 31 (1), 24.

(8) Lee, B. W. K.; Van Lanen, S. G.; Iwata-Reuyl, D. Biochemistry 2007, 46 (44), 12844.

(9) Motorin, Y.; Helm, M. Biochemistry 2010, 49 (24), 4934.

(10) Lorenz, C.; Lünse, C.; Mörl, M. Biomolecules 2017, 7 (2), 35.

(11) Jackman, J. E.; Alfonzo, J. D. WIREs RNA 2013, 4 (1), 35.

(12) Kasai, H.; Goto, M.; Ikeda, K.; Zama, M.; Mizuno, Y.; Takemura, S.; Matsuura, S.; Sugimoto, T.; Goto, T. Biochemistry 1976, $15(4), 898$.

(13) Blobstein, S. H.; Grunberger, D.; Weinstein, I. B.; Nakanishi, K. Biochemistry 1973, 12 (2), 188.

(14) Feinberg, A. M.; Nakanishi, K.; Barciszewski, J.; Rafalski, A. J.; Augustyniak, H.; Wiewiorowski, M. J. Am. Chem. Soc. 1974, 96 (25), 7797.

(15) Nakanishi, K.; Blobstein, S.; Funamizu, M.; Furutachi, N.; Van Lear, G.; Grunberger, D.; Lanks, K. W.; Weinstein, I. B. Nature New Biol. 1971, 234 (47), 107.

(16) de Crécy-Lagard, V.; Brochier-Armanet, C.; Urbonavičius, J.; Fernandez, B.; Phillips, G.; Lyons, B.; Noma, A.; Alvarez, S.; Droogmans, L.; Armengaud, J.; Grosjean, H. Mol. Biol. Evol. 2010, 27 (9), 2062.

(17) Waas, W. F.; de Crécy-Lagard, V.; Schimmel, P. J. Biol. Chem. 2005, 280 (45), 37616.

(18) Noma, A.; Kirino, Y.; Ikeuchi, Y.; Suzuki, T. EMBO J. 2006, 25 (10), 2142.

(19) Waas, W. F.; Druzina, Z.; Hanan, M.; Schimmel, P. J. Biol. Chem. 2007, 282 (36), 26026.

(20) Hatfield, D.; Feng, Y. X.; Lee, B. J.; Rein, A.; Levin, J. G.; Oroszlan, S. Virology 1989, 173 (2), 736.

(21) Kasai, H.; Yamaizumi, Z.; Kuchino, Y.; Nishimura, S. Nucleic Acids Res. 1979, 6 (3), 993.

(22) McCloskey, J. A.; Crain, P. F.; Edmonds, C. G.; Gupta, R.; Hashizume, T.; Phillipson, D. W.; Stetter, K. O. Nucleic Acids Res. 1987, 15 (2), 683.

(23) McCloskey, J. A.; Graham, D. E.; Zhou, S.; Crain, P. F.; Ibba, M.; Konisky, J.; Söll, D.; Olsen, G. J. Nucleic Acids Res. 2001, 29 (22), 4699.

(24) Itaya, T.; Kanai, T.; Sawada, T. Chem. Pharm. Bull. 2002, 50 (4), 547.

(25) Noon, K. R.; Guymon, R.; Crain, P. F.; McCloskey, J. A.; Thomm, M.; Lim, J.; Cavicchioli, R. J. Bacteriol. 2003, 185 (18), 5483.

(26) Zhou, S.; Sitaramaiah, D.; Noon, K. R.; Guymon, R.; Hashizume, T.; McCloskey, J. A. Bioorg. Chem. 2004, 32 (2), 82.

(27) Iyer, L. M.; Abhiman, S.; de Souza, R. F.; Aravind, L. Nucleic Acids Res. 2010, 38 (16), 5261.

(28) Urbonavičius, J.; Meškys, R.; Grosjean, H. RNA 2014, 20 (6), 747.

(29) Sample, P. J.; Kořený, L.; Paris, Z.; Gaston, K. W.; Rubio, M. A. T.; Fleming, I. M. C.; Hinger, S.; Horáková, E.; Limbach, P. A.; Lukeš, J.; Alfonzo, J. D. Nucleic Acids Res. 2015, 43 (8), 4262.

(30) Björk, G. R.; Jacobsson, K.; Nilsson, K.; Johansson, M. J. O.; Byström, A. S.; Persson, O. P. EMBO J. 2001, 20 (1-2), 231.

(31) Droogmans, L.; Grosjean, H. EMBO J. 1987, 6 (2), 477.

(32) Young, A. P.; Bandarian, V. Biochemistry 2015, 54 (23), 3569. 
(33) Young, A. P.; Bandarian, V. Biochemistry 2011, 50 (49), 10573.

(34) Young, A. P.; Bandarian, V. Curr. Opin. Chem. Biol. 2013, 17 (4), 613.

(35) Perche-Letuvée, P.; Kathirvelu, V.; Berggren, G.; Clemancey, M.; Latour, J.-M.; Maurel, V.; Douki, T.; Armengaud, J.; Mulliez, E.; Fontecave, M.; Garcia-Serres, R.; Gambarelli, S.; Atta, M. J. Biol. Chem. 2012, 287 (49), 41174.

(36) Perche-Letuvée, P.; Molle, T.; Forouhar, F.; Mulliez, E.; Atta, M. RNA Biol. 2014, 11 (12), 1508.

(37) Mulliez, E.; Duarte, V.; Arragain, S.; Fontecave, M.; Atta, M. Front. Chem. 2017, 5, 1.

(38) Brown, S.; Babbitt, P. Curr. Protoc. Bioinformatics 2014, 48, 2.10.1.

(39) Frey, P. A.; Hegeman, A. D.; Ruzicka, F. J. Crit. Rev. Biochem. Mol. Biol. 2008, 43 (1), 63.

(40) Berkovitch, F.; Nicolet, Y.; Wan, J. T.; Jarrett, J. T.; Drennan, C. L. Science 2004, 303, 76.

(41) Cicchillo, R. M.; Iwig, D. F.; Jones, A. D.; Nesbitt, N. M.; Baleanu-Gogonea, C.; Souder, M. G.; Tu, L.; Booker, S. J. Biochemistry 2004, 43 (21), 6378.

(42) McLaughlin, M. I.; Lanz, N. D.; Goldman, P. J.; Lee, K.-H.; Booker, S. J.; Drennan, C. L. Proc. Natl. Acad. Sci. U. S. A. 2016, 113 (34), 9446.

(43) Hänzelmann, P.; Schindelin, H. Proc. Natl. Acad. Sci. U. S. A. 2006, 103 (18), 6829.

(44) Flühe, L.; Knappe, T. A.; Gattner, M. J.; Schäfer, A.; Burghaus, O.; Linne, U.; Marahiel, M. A. Nat. Chem. Biol. 2012, 8 (4), 350.

(45) Grove, T. L.; Lee, K.-H., St; Clair, J.; Krebs, C.; Booker, S. J. Biochemistry 2008, 47 (28), 7523.

(46) Lee, K.-H.; Saleh, L.; Anton, B. P.; Madinger, C. L.; Benner, J. S.; Iwig, D. F.; Roberts, R. J.; Krebs, C.; Booker, S. J. Biochemistry 2009, 48 (42), 10162.

(47) Forouhar, F.; Arragain, S.; Atta, M.; Gambarelli, S.; Mouesca, J.M.; Hussain, M.; Xiao, R.; Kieffer-Jaquinod, S.; Seetharaman, J.; Acton, T. B.; Montelione, G. T.; Mulliez, E.; Hunt, J. F.; Fontecave, M. Nat. Chem. Biol. 2013, 9 (5), 333.

(48) Arragain, S.; Handelman, S. K.; Forouhar, F.; Wei, F.-Y.; Tomizawa, K.; Hunt, J. F.; Douki, T.; Fontecave, M.; Mulliez, E.; Atta, M. J. Biol. Chem. 2010, 285 (37), 28425.

(49) Lees, N. S.; Hänzelmann, P.; Hernandez, H. L.; Subramanian, S.; Schindelin, H.; Johnson, M. K.; Hoffman, B. M. J. Am. Chem. Soc. 2009, 131 (26), 9184.

(50) Suzuki, Y.; Noma, A.; Suzuki, T.; Senda, M.; Senda, T.; Ishitani, R.; Nureki, O. J. Mol. Biol. 2007, 372 (5), 1204.

(51) Goto-Ito, S.; Ishii, R.; Ito, T.; Shibata, R.; Fusatomi, E.; Sekine, S. I.; Bessho, Y.; Yokoyama, S. Acta Crystallogr., Sect. D: Biol. Crystallogr. 2007, 63 (10), 1059.

(52) Kathirvelu, V.; Perche-Letuv e, P. L.; Latour, J.-M.; Atta, M.; Forouhar, F.; Gambarelli, S.; Garcia-Serres, R. Dalton Trans. 2017, 11, 134.

(53) Thoden, J. B.; Holden, H. M. J. Biol. Chem. 2005, 280 (38), 32784 .

(54) Otwinowski, Z.; Minor, W. Methods Enzymol. 1997, 276, 307.

(55) McCoy, A. J.; Grosse-Kunstleve, R. W.; Adams, P. D.; Winn, M. D.; Storoni, L. C.; Read, R. J. J. Appl. Crystallogr. 2007, 40, 658.

(56) Emsley, P.; Lohkamp, B.; Scott, W. G.; Cowtan, K. Acta Crystallogr., Sect. D: Biol. Crystallogr. 2010, 66, 486.

(57) Adams, P. D.; Afonine, P. V.; Bunkóczi, G.; Chen, V. B.; Davis, I. W.; Echols, N.; Headd, J. J.; Hung, L.-W.; Kapral, G. J.; GrosseKunstleve, R. W.; McCoy, A. J.; Moriarty, N. W.; Oeffner, R.; Read, R. J.; Richardson, D. C.; Richardson, J. S.; Terwilliger, T. C.; Zwart, P. H. Acta Crystallogr., Sect. D: Biol. Crystallogr. 2010, 66, 213.

(58) Lebedev, A. A.; Young, P.; Isupov, M. N.; Moroz, O. V.; Vagin, A. A.; Murshudov, G. N. Acta Crystallogr., Sect. D: Biol. Crystallogr. 2012, 68, 431.

(59) Dowling, D. P.; Bruender, N. A.; Young, A. P.; McCarty, R. M.; Bandarian, V.; Drennan, C. L. Nat. Chem. Biol. 2014, 10 (2), 106.

(60) Bruender, N. A.; Grell, T. A. J.; Dowling, D. P.; McCarty, R. M.; Drennan, C. L.; Bandarian, V. J. Am. Chem. Soc. 2017, 139 (5), 1912.
(61) The PyMol Molecular Graphics System, version 2.0; Schrödinger, LLC.

(62) Baker, N. A.; Sept, D.; Joseph, S.; Holst, M. J.; McCammon, J. A. Proc. Natl. Acad. Sci. U. S. A. 2001, 98 (18), 10037.

(63) Davis, K. M.; Schramma, K. R.; Hansen, W. A.; Bacik, J. P.; Khare, S. D.; Seyedsayamdost, M. R.; Ando, N. Proc. Natl. Acad. Sci. U. S. A. 2017, 114 (39), 10420.

(64) Grove, T. L.; Himes, P. M.; Hwang, S.; Yumerefendi, H.; Bonanno, J. B.; Kuhlman, B.; Almo, S. C.; Bowers, A. A. J. Am. Chem. Soc. 2017, 139 (34), 11734.

(65) Fenwick, M. K.; Li, Y.; Cresswell, P.; Modis, Y.; Ealick, S. E. Proc. Natl. Acad. Sci. U. S. A. 2017, 114 (26), 6806.

(66) Harmer, J. E.; Hiscox, M. J.; Dinis, P. C.; Fox, S. J.; Iliopoulos, A.; Hussey, J. E.; Sandy, J.; Van Beek, F. T.; Essex, J. W.; Roach, P. L. Biochem. J. 2014, 464 (1), 123.

(67) Benjdia, A.; Heil, K.; Barends, T. R. M.; Carell, T.; Schlichting, I. Nucleic Acids Res. 2012, 40 (18), 9308.

(68) Boal, A. K.; Grove, T. L.; McLaughlin, M. I.; Yennawar, N. H.; Booker, S. J.; Rosenzweig, A. C. Science 2011, 332 (6033), 1089.

(69) Lepore, B. W.; Ruzicka, F. J.; Frey, P. A.; Ringe, D. Proc. Natl. Acad. Sci. U. S. A. 2005, 102 (39), 13819.

(70) Hänzelmann, P.; Schindelin, H. Proc. Natl. Acad. Sci. U. S. A. 2004, 101 (35), 12870.

(71) Nicolet, Y.; Rubach, J. K.; Posewitz, M. C.; Amara, P.; Mathevon, C.; Atta, M.; Fontecave, M.; Fontecilla-Camps, J. C. J. Biol. Chem. 2008, 283 (27), 18861.

(72) Bridwell-Rabb, J.; Zhong, A.; Sun, H. G.; Drennan, C. L.; Liu, H.-W. Nature 2017, 544 (7650), 322.

(73) Sofia, H. J.; Chen, G.; Hetzler, B. G.; Reyes-Spindola, J. F.; Miller, N. E. Nucleic Acids Res. 2001, 29 (5), 1097.

(74) Schwalm, E. L.; Grove, T. L.; Booker, S. J.; Boal, A. K. Science 2016, 352 (6283), 309.

(75) Dowling, D. P.; Vey, J. L.; Croft, A. K.; Drennan, C. L. Biochim. Biophys. Acta, Proteins Proteomics 2012, 1824 (11), 1178.

(76) Grell, T. A. J.; Goldman, P. J.; Drennan, C. L. J. Biol. Chem. 2015, 290 (7), 3964.

(77) Quitterer, F.; List, A.; Eisenreich, W.; Bacher, A.; Groll, M. Angew. Chem., Int. Ed. 2012, 51 (6), 1339.

(78) Nicolet, Y.; Pagnier, A.; Zeppieri, L.; Martin, L.; Amara, P.; Fontecilla-Camps, J. C. ChemBioChem 2015, 16 (3), 397.

(79) Vey, J. L.; Drennan, C. L. Chem. Rev. 2011, 111 (4), 2487.

(80) Roberts, R. J.; Cheng, X. Annu. Rev. Biochem. 1998, 67 (1), 181.

(81) Grove, T. L.; Ahlum, J. H.; Qin, R. M.; Lanz, N. D.; Radle, M. I.; Krebs, C.; Booker, S. J. Biochemistry 2013, 52 (17), 2874. 